\title{
Cluster of differentiation 147 mediates chemoresistance in breast cancer by affecting vacuolar $\mathrm{H}^{+}$-ATPase expression and activity
}

\author{
YEHONG KUANG ${ }^{1}$, SHOUMAN WANG ${ }^{2}$, LILI TANG $^{2}$, JIAN HAI $^{2}$, GUOJIAO YAN $^{2}$ and LIQIU LIAO ${ }^{2}$ \\ Departments of ${ }^{1}$ Dermatology and ${ }^{2}$ Breast Surgery, Hunan Clinical Meditech Research Center for Breast Cancer, \\ Xiangya Hospital, Central South University, Changsha, Hunan 410008, P.R. China
}

Received April 9, 2017; Accepted February 1, 2018

DOI: $10.3892 /$ ol.2018.8199

\begin{abstract}
Vacuolar $\mathrm{H}^{+}$-ATPase (V-ATPase) serves a key role in adjusting and maintaining the intracellular $\mathrm{pH}$, as well as in regulating the drug resistance of tumor cells. In recent years, the expression level of V-ATPase has been considered to be able to predict the sensitivity of breast cancer cells to chemotherapy drugs. Cluster of differentiation 147 (CD147) is known to serve a key role in the development and progression of breast cancer. The present study aimed to identify the role CD147 and V-ATPase in chemoresistance in breast cancer, and to characterize the regulation of CD147 on V-ATPase. Firstly, the expression levels of CD147 and V-ATPase were detected in chemotherapy-resistance breast cancer samples. It was demonstrated that V-ATPase was highly expressed in chemotherapy-resistance breast cancer samples, and that its expression was correlated with CD147 expression. Subsequently, MCF-7 and MDA-MB-231 cells were used to study the regulatory effect of CD147 on the expression and function of V-ATPase. Gene transfection or small interfering RNA transfection were used to control the expression of CD147 in the two cell lines. The results revealed that the overexpression of CD147 increased the expression of V-ATPase in MCF-7 cells, whereas CD147 knockdown decreased V-ATPase expression in MDA-MB-231 cells. It was also observed that CD147 affected the V-ATPase activity, regulating the transmembrane $\mathrm{pH}$ gradient of cancer cells. These results demonstrated that CD147 was associated with the sensitivity of chemotherapeutic drugs of epirubicin and docetaxel, while pantoprazole was able to partially reverse the CD147-mediated chemoresistance in breast cancer. Therefore, the current study provided a possible mechanism for further examination of drug resistance in breast cancer.
\end{abstract}

Correspondence to: Dr Liqiu Liao, Department of Breast Surgery, Hunan Clinical Meditech Research Center for Breast Cancer, Xiangya Hospital, Central South University, 87 Xiangya Road, Changsha, Hunan 410008, P.R. China

E-mail: aq301981@163.com

Key words: breast cancer, cluster of differentiation 147, vacuolar $\mathrm{H}^{+}$-ATPase, chemoresistance, acidic tumor environment

\section{Introduction}

Breast cancer is the most common malignant tumor and the leading cause of cancer-associated mortality cases in females in developing countries (1). Despite major advances in biomedical research and the development of novel therapeutic agents and treatment strategies, chemotherapy is an irreplaceable and effective comprehensive treatment of breast cancer. Currently, epirubicin and docetaxel are the most commonly used drugs in breast cancer treatment (2). However, $~ 30 \%$ of all patients with early-stage breast cancer develop recurrent disease due to acquired resistance (3). In addition, due to the presence of intrinsic resistance, numerous patients undergo treatments that are ineffective, resulting in a delay in receiving other more suitable therapies and in adverse side effects (4). Chemoresistance has become a major obstacle during the treatment of breast cancer; therefore, it is critical to understand the mechanisms underlying the development of breast cancer chemoresistance and to develop novel treatment strategies for this tumor.

Several mechanisms have been identified that underlie the intrinsic and acquired chemoresistance, including deletion of receptors, altered drug metabolism, impaired drug uptake, various mechanisms of anti-apoptosis, increased DNA damage repair, quantitative and qualitative alterations in drug targets, and increased drug efflux (5). Numerous previous studies have focused on pathways that modulate the cancer cell sensitivity, including the transmembrane ATP-dependent efflux pump P-glycoprotein (P-gp) $(6,7)$, human epidermal growth factor receptor 2/Erb-b2 receptor tyrosine kinase 2 (8), B-cell lymphoma-2 family proteins (9) and various microRNAs (10). The tumor microenvironment is important for tumor cell survival at the primary lesion and distant metastatic sites, and its role in tumor drug resistance has received increasing attention (11). Accumulating evidence has demonstrated that an acidic tumor microenvironment leads to a more aggressive phenotype and increases the drug resistance by elevating the expression of $\mathrm{P}$-gp, suggesting that management of the tumor $\mathrm{pH}$ value and inhibition of the proton-sensing system blockade are important in preventing metastasis, as well as improving drug efficacy (5,12-14). Compared with normal cells, tumor cells have been observed to exhibit low extracellular $\mathrm{pH}\left(\mathrm{pH}_{\mathrm{e}}\right)$ and high intracellular $\mathrm{pH}\left(\mathrm{pH}_{\mathrm{i}}\right)$ characteristics (15). The particular transmembrane $\mathrm{pH}$ gradient occurring between the intracellular and extracellular spaces has a negative impact on the distribution, 
uptake and bioavailability of weak base antineoplastic drugs, eventually leading to chemoresistance $(5,14,16)$. It has been reported that exposure to proton pump inhibitors (PPIs) was able to resensitize multidrug-resistant cells to chemotherapeutic drugs, suggesting that counteracting the acidity of the tumor microenvironment or altering the transmembrane $\mathrm{pH}$ gradient of tumor cells may overcome the mechanisms of chemoresistance $(5,17)$.

Vacuolar $\mathrm{H}^{+}$-ATPase (V-ATPase), a key multi-subunit proton pump, serves an important role in the acidic microenvironment of the tumor. It relies on the energy transfer protons generated by the hydrolysis of ATP to produce the electrochemical gradient of the transmembrane and to regulate the transmembrane $\mathrm{pH}$ gradient (18). V-ATPase has been considered to be one of the important targets for overcoming an acidic tumor microenvironment $(5,18)$. In addition, several studies have demonstrated that PPIs, which directly inhibit V-ATPase at the cellular level, reverted chemoresistance in drug-resistant tumors and directly induced tumor cell death, indicating that targeting V-ATPase may be an option for reversing multidrug resistance (17).

Cluster of differentiation 147 (CD147) has been identified as a novel tumor marker for breast cancer. It is involved in a variety of malignant biological behaviors, including tumor invasion, metastasis, angiogenesis, energy metabolism and multidrug resistance (19-21). CD147 combines with a number of other molecules and forms a polymer on the cell membrane in order to regulate the biological function of other molecules $(22,23)$. Slomiany et al (24) reported that CD147 and monocarboxylate transporters (MCTs) co-localized on the cell membrane and participated in lactate efflux, regulating the $\mathrm{pH}$ value in the tumor microenvironment and thus resulting in chemoresistance in breast cancer $(24,25)$. Our earlier study (22) demonstrated that CD147 is highly expressed in chemotherapy-resistant breast cancer. Furthermore, CD147 was observed to form a complex with ATP-binding cassette sub-family $G$ member 2 (ABCG2) and regulate ABCG2 expression, in order to induce chemoresistance via affecting the location and dimerization of ABCG2. Despite the involvement of both CD147 and V-ATPase in chemoresistance, there are currently no studies on the mutual interaction between CD147 and V-ATPase, and their roles in drug sensitivity in breast cancer.

In the present study, the expression of V-ATPase in chemotherapy-resistant breast cancer samples and its correlation with CD147 expression were investigated. Subsequently, MCF-7 and MDA-MB-231 breast cancer cell lines were used to investigate the role of the interaction between CD147 and $\mathrm{V}$-ATPase in breast cancer chemoresistance. The results demonstrated that CD147 regulated the expression and activity of V-ATPase to mediate the chemotherapy drug resistance of breast cancer cells.

\section{Materials and methods}

Cell culture. MCF-7 and MDA-MB-231 cells were obtained from the Shanghai Institute of Cell Biology at the Chinese Academy of Sciences (Shanghai, China). The cells were maintained in high-glucose Dulbecco's modified Eagle's medium (DMEM; Thermo Fisher Scientific, Inc., Waltham, MA, USA), supplemented with $10 \%$ fetal bovine serum (Gibco; Thermo Fisher Scientific, Inc.) $100 \mathrm{U} / \mathrm{ml}$ penicillin-G (Jingmei Biotech Co., Ltd., Shenzhen, China) and $100 \mu \mathrm{g} / \mathrm{ml}$ streptomycin (Jingmei Biotech Co., Ltd.) at $37^{\circ} \mathrm{C}$ in a humidified incubator with $5 \% \mathrm{CO}_{2}$.

Establishment of transfected cells. The pGC-Fu-CD147 plasmid encoding CD147 cDNA and the pSUPER/CD147 short hairpin (sh)RNA vector targeting human CD147 mRNA were constructed and packaged with a lentivirus by Shanghai GeneChem Co., Ltd. (Shanghai, China) as described previously $(22,26)$. Briefly, the cDNA containing the entire region of human CD147 was prepared by Agel enzyme digestion (Shanghai Genechem Co., Ltd.) and cloned into the pGCFU vector (Shanghai GeneChem Co., Ltd.). The shRNA sequence was: 5'-GATCCCCTGACAAAGGCA AGAACGTCTTC AAGAGAGACGTTCTTGCCTTTGTCATTTTTGGAAA-3. The sequence has no homology to other human genes, as determined by nucleotide-nucleotide Basic Local Alignment Search Tool search in a previous study (27). A control scrambled sequence (5'-TTCTCCGAACGTGTACGT-3') with no homology to other genes was annealed and ligated into the linearized plasmid using T4 DNA ligase (Promega Corporation, Madison, WI, USA). Chemically competent Escherichia coli DH5 $\alpha$ (Takara Bio., Inc., Otsu, Japan) were transformed, and positive transformants were isolated using ampicillin- $\mathrm{G}$ (Jingmei Biotech Co., Ltd.) selection (100 ng/ml) and amplified using the EndoFree Plasmid Maxi kit (Qiagen China Co., Ltd., Shanghai, China) according to the manufacturer's protocol. The successful insertion of siRNA into pSUPER (GeneChem Co., Ltd.) was confirmed by DNA sequencing, PCR and restriction endonuclease digestion which were performed by Genechem Co., Ltd. Subsequently, the plasmids were successfully packaged with the lentivirus by using the Lenti-Easy Packaging System (LPK 001; Genechem Co., Ltd.). MCF-7 cells with low-expression CD147 (22) were transfected with the lentivirus vector containing the pGC-Fu-CD147 plasmid or green fluorescent protein (GFP) vector (Shanghai GeneChem Co., Ltd.), which served as a control, and MDA-MB-231 cells overexpressing CD147 (25) were transfected with the lentivirus vector containing pSUPER/CD147 shRNA or a GFP vector using the FuGENE 6 transfection reagent (Roche Diagnostics GmbH, Mannheim, Germany), respectively. After $48 \mathrm{~h}$ transfection, the MCF-7 and MDA-MB-231 cells were then grown in DMEM containing $1 \mu \mathrm{g} / \mathrm{ml}$ puromycin (Sigma-Aldrich; Merck KGaA, Darmstadt, Germany) for 5-7 days. The cells were then maintained in DMEM containing $0.5 \mu \mathrm{g} / \mathrm{ml}$ puromycin for at least 4 weeks, until the final stable single cell clones were harvested and verified by reverse transcription-quantitative PCR (RT-qPCR) and western blot analyses, as described below. The 4 stable transfected cell lines were MCF-7 control (MCF-7/CON), CD147 overexpression (MCF-7/CD), MDA-MB-231 control (MDA-MB-231/CON) and CD147 knockdown cells (MDA-MB-231/si).

RNA isolation and RT-qPCR analysis. Total RNA was extracted from the cells with the RNeasy Plus Mini kit (Qiagen China Co., Ltd.), and the total RNA concentration was measured spectrophotometrically from the ratio of absorbance at 260 and $280 \mathrm{~nm}$ using a NanoDrop ND-1000 (NanoDrop 
Technologies; Thermo Fisher Scientific, Inc., Wilmington, DE, USA). A total of $2 \mu \mathrm{g}$ RNA samples were used to synthesize cDNA using the Super Script VILO cDNA Synthesis kit (Invitrogen; Thermo Fisher Scientific, Inc.). Amplification was subsequently performed on an ABI PRISM 7900HT (Applied Biosystems; Thermo Fisher Scientific, Inc.) in a final volume of $10 \mu 1$, using $5 \mu$ 1 Power SYBR ${ }^{\circledR}$-Green PCR Master Mix (Applied Biosystems; Thermo Fisher Scientific, Inc.) and $0.5 \mu \mathrm{M}$ of each primer. Thermocycling conditions for CD147 and $\beta$-actin were as follows: Template pre-denaturation $\left(30 \mathrm{sec}\right.$ at $\left.95^{\circ} \mathrm{C}\right)$, denaturation $\left(15 \mathrm{sec}\right.$ at $\left.95^{\circ} \mathrm{C}\right)$ and annealing and extension $\left(25 \mathrm{sec}\right.$ at $\left.60^{\circ} \mathrm{C}\right)$ for 40 cycles. The protocol for melting curve analysis was as follows: $15 \mathrm{sec}$ at $95^{\circ} \mathrm{C}$, $1 \mathrm{~min}$ at $60^{\circ} \mathrm{C}$ and $15 \mathrm{sec}$ at $95^{\circ} \mathrm{C}$. The target primers were as follows: CD147 forward primer, 5'-GCAGCGGTTGGA GGTTGT-3'; and reverse primer, 5'-AGCCACGATGCCCAG GAAGG-3'; $\beta$-actin forward primer, 5'-GTCATCACCATT GGCAATGAG-3'; and reverse primer, 5'-CGTCACACTTCA TGATGGAGTT-3'. Target gene primers were synthesized by Sangon Biotech Co., Ltd. (Shanghai, China), and amplification of endogenous $\beta$-actin was used as an internal control. $2^{-\Delta \Delta C q}$ method was used to quantify as previously described (28).

Western blot analysis. Cells were lysed in radioimmunoprecipitation assay buffer (Thermo Fisher Scientific, Inc.) and sonicated on ice for three times, $5 \mathrm{sec}$ at $20 \mathrm{KHz}$. The cell lysates was then centrifuged at $14,000 \mathrm{xg}$ for $20 \mathrm{~min}$ at $4^{\circ} \mathrm{C}$, and the supernatant was collected. Protein concentration was quantified by Bio-Rad Protein Assay (cat. no. 5000006; Bio-Rad Laboratories, Inc., Hercules, CA, USA). Subsequently, protein $(50 \mu \mathrm{g})$ samples were subjected to $10 \%$ SDS-PAGE (GenScript Biotech Corporation, Piscataway, NJ, USA) and transferred to the polyvinylidene difluoride membranes. The samples were then blocked with $3 \%$ bovine serum albumin (BSA) for $1 \mathrm{~h}$ at room temperature, followed by incubation with monoclonal antibodies against CD147 (1:2,000; ab212856; Abcam, Cambridge, UK) or anti-GAPDH (1:500; sc-FL335; Santa Cruz Biotechnology, Inc., Dallas, TX, USA). Secondary horseradish peroxidase-conjugated polyclonal goat anti-mouse IgG antibodies (1:5,000; sc-2005; Santa Cruz Biotechnology, Inc., Dallas, TX, USA) were then incubated with the membranes for $1 \mathrm{~h}$ at room temperature. The signal from antibody-conjugated horseradish peroxidase was visualized by applying SuperSignal ${ }^{\mathrm{TM}}$ West Pico Chemiluminescent Substrate (Thermo Fisher Scientific, Inc., Waltham, MA, USA) and exposing to X-ray film. The GAPDH expression was used as an internal control and the grayscale ratios of CD147 to GAPDH were calculated.

Patient samples. A retrospective analysis comparing the chemotherapy response to the protein levels of CD147 and V-ATPase was also conducted in the present study. The study design was reviewed and approved by the Research Ethics Board of the Research Institute at Xiangya Hospital (Central South University, Changsha, China; no. 201403152). Informed consent was obtained from all participants whose tissue samples were included in the study. The criteria for inclusion into the current retrospective analysis were as follows: i) A confirmed diagnosis of invasive ductal breast cancer by pathologic examination (29) and receiving treatment by neoadjuvant chemotherapy; ii) patients had not received any previous treatment; iii) patients receiving only four cycles of based neoadjuvant chemotherapy with the AC (involving pirarubicin and cyclophosphamide) or EC (involving epirubcin and cyclophosphamide) regimens prior to surgery (22); and iv) availability of complete hospital record, including chemotherapy efficacy evaluation. The clinical Response to AC/EC chemotherapy was evaluated by the decrease in tumor size and classified according to the Response Evaluation Criteria In Solid Tumors (RECIST) criteria (30). Patients demonstrating complete or partial remission were classified as chemotherapy-sensitive cases, while those with stable or progressive disease were classified as chemotherapy-resistant cases. A total of 84 patients with breast cancer met all the criteria above between February 2014 and February 2015 in the Affiliated Xiangya Hospital of Central South University (Changsha, China). According to the RECIST criteria, the 84 patients were divided into two groups: A chemotherapy-sensitive group (63 cases) and a chemotherapy-resistant group (21 cases).

Immunohistochemical assay. Biopsy samples of the included patients with breast cancer were collected and embedded in paraffin by the Department of Pathology of the Xiangya Hospital of Central South University, and then were stored at room temperature. The paraffin-embedded samples were stored at temperature and subjected to immunohistochemical assay using standard procedures to examine their CD147 and V-ATPase content. Briefly, $5 \mu \mathrm{m}$ tissue sections were deparaffinized and blocked with $0.3 \%$ hydrogen peroxide for $30 \mathrm{~min}$ at room temperature. Subsequent to heating for $20 \mathrm{~min}$ at $100^{\circ} \mathrm{C}$ in a microwave oven for antigen retrieval and blocking with normal rabbit serum for $20 \mathrm{~min}$ at room temperature (cat. no. ab166640; Abcam), the sections were incubated with primary antibodies at $4^{\circ} \mathrm{C}$ overnight, including CD147 (1:200; cat. no. ab212856; Abcam) and V-ATPase (1:200; cat. no. sc-69088; Santa Cruz Biotechnology, Inc. Dallas, TX, USA), or with PBS as the negative control. A 2-step Plus Poly-HRP Anti-Mouse/Goat IgG detection system (OriGene Technologies, Inc., Beijing, China) was then applied according to the manufacturer's protocol, followed by DAB visualization. Two pathologists blinded to the markers examined the immunohistochemically stained sections independently. Five fields-of-view at a magnification of $x 400$ were randomly selected for analysis in each section. For the semi-quantitative analysis of the immunoreactivity of CD147 and V-ATPase, $\mathrm{H}$-score (31) was used to assess the following parameters: i) Intensity of staining, which was scored between 0 and 3, with 0 assigned upon absence of staining, 1 for weak staining, 2 for moderate staining, 3 for strong staining; and ii) the percentage of positive cells. The range of possible scores was between 0 and 300 .

Immunofluorescence assay. Cells were fixed with $100 \%$ ice-cold methanol for $10 \mathrm{~min}$ and blocked with $10 \%$ BSA for $1 \mathrm{~h}$ at room temperature. Subsequent to washing with PBS, the cells were incubated for $2 \mathrm{~h}$ at room temperature with primary antibodies against CD147 (1:200; cat. no. ab212856; Abcam) and V-ATPase (1:100; cat. no. sc-69088; Santa Cruz Biotechnology, Inc. Dallas, TX, USA), followed by incubation with secondary antibodies, including anti-mouse Cy3 (1:200; 
cat. no. AP192C; EMD Millipore, Billerica, MA, USA) or anti-goat FITC (1:500; cat. no. ab6881; Abcam) antibodies for $1 \mathrm{~h}$ at room temperature. Cells were then rinsed with PBS for three times and mounted in a ProLong Gold Antifade reagent with DAPI (Invitrogen; Thermo Fisher Scientific, Inc.). Images were captured using a Leica fluorescence microscope (Leica Microsystems GmbH, Wetzlar, Germany).

Measurement of plasma membrane V-ATPase activity. The transmembrane protein was initially extracted using a transmembrane protein extraction kit (cat. no. GMS30039.2; Genmed Pharmaceutical Technology Co., Ltd., Shanghai, China), and the protein concentration was quantified by a Bio-Rad protein assay kit (cat. no. 5000006; Bio-Rad Laboratories, Inc.) according to the manufacturer's instructions. Subsequently, measurement of the plasma membrane V-ATPase activity was performed using a V-ATPase activity detection colorimetric kit (cat. no. GMS50247.1; Genmed Pharmaceutical Technology Co., Ltd.), according to the manufacturer's protocol.

Measurements of $\mathrm{pH}_{i}$ and $\mathrm{pH}_{e}$ values. The $\mathrm{pH}_{\mathrm{i}}$ value was measured in the monolayers using the $\mathrm{pH}$-sensitive fluorescent probe 2',7'-bis-(2-carboxyethyl)-5-carboxyfluorescein/acetoxymethyl ester (BCECF/AM; sc-202492; Santa Cruz Biotechnology, Inc.), as previously described $(17,32)$. Briefly, in order to determine the $\mathrm{pH}_{\mathrm{i}}$, the standard buffers were initially prepared. The $\mathrm{pH}$ standard buffer A consisted of $133 \mathrm{mM} \mathrm{KCl}, 7 \mathrm{mM}$ choline chloride, $1 \mathrm{mM} \mathrm{CaCl}_{2}, 2 \mathrm{mM}$ $\mathrm{KH}_{2} \mathrm{PO}_{4}, 5 \mathrm{mM}$ glucose and $6 \mathrm{mM}$ HEPES, and the $\mathrm{pH}$ values of solutions of buffer $\mathrm{A}$ were adjusted to 6.2, 6.4, 6.6, 6.8, 7.0, 7.2, 7.4 and 7.6, respectively. Buffer B contained $135 \mathrm{mM}$ $\mathrm{NaCl}, 5 \mathrm{mM} \mathrm{KCl}, 1.8 \mathrm{mM} \mathrm{CaCl}{ }_{2}, 0.8 \mathrm{mM} \mathrm{MgSO}_{4}, 5 \mathrm{mM}$ glucose and $10 \mathrm{mM}$ HEPES, and the $\mathrm{pH}$ of this buffer was adjusted to 7.4. Subsequently, a standard curve was established. For this, cells (MCF-7 or MDA-MB-231 cells) were cultured for $24 \mathrm{~h}$ in 6 -well plates at a density of $1 \times 10^{5}$ cells per well under the aforementioned cell culture conditions. The culture medium was removed, and the cells were washed with buffer $\mathrm{B}$ twice for $5 \mathrm{~min}$ each time, followed by addition of buffer B containing BCECF/AM $(1 \mu \mathrm{l} / 1 \mathrm{ml} ; 5 \mu \mathrm{M})$ and incubation for $1 \mathrm{~h}$ at $37^{\circ} \mathrm{C}$. The supernatant was removed and the cells were washed twice with each given $\mathrm{pH}$ value of buffer A, followed by addition of buffer A containing nigericin $(1 \mu \mathrm{l} / 1 \mathrm{ml} ; 5 \mu \mathrm{M})$ into each well and incubation for $15 \mathrm{~min}$ under normal conditions. The cells were then trypsinized and resuspended with $1 \mathrm{ml}$ of each given $\mathrm{pH}$ value of buffer A. Next, the BCECF fluorescence intensity was recorded by flow cytometry (33) at excitation light and emission light wavelengths of 490 and $530 \mathrm{~nm}$, respectively. Bivariate correlation analysis between the fluorescence intensity at $490 \mathrm{~nm}$ and the $\mathrm{pH}$ value was performed, and then the $\mathrm{pH}_{\mathrm{i}}$ standard curve was developed. Finally, following the measurement of the $\mathrm{pH}_{\mathrm{i}}$ value of transfected cells as described earlier but using buffer B without nigericin instead of buffer A, the fluorescent intensity at $490 \mathrm{~nm}$ was recorded and the $\mathrm{pH}_{\mathrm{i}}$ value was calculated according to the $\mathrm{pH}_{\mathrm{i}}$ standard curve. The $\mathrm{pH}_{\mathrm{e}}$ values of the culture medium after 24-h incubation were measured by a Calibration Check Microprocessor $\mathrm{pH}$ Meter (FE28K; Mettler Toledo, Columbus, OH, USA).
Cell sensitivity to drugs by sulforhodamine B (SRB) assay. Cells were seeded into 96-well tissue culture plates at a density of $5 \times 10^{3}$ cells per well. Following overnight incubation, various concentrations of the anticancer drugs epirubicin or docetaxel (Sigma-Aldrich; Merck KGaA, Darmstadt, Germany) was added into the medium and cultured for $72 \mathrm{~h}$, and then the cell viability was measured by an SRB assay $(34,35)$. Briefly, the cells were fixed with $10 \%$ trichloroacetic acid for $30 \mathrm{~min}$ at $4^{\circ} \mathrm{C}$ and stained with $0.4 \%$ (w/v) SRB (Sigma-Aldrich; Merck KGaA, Darmstadt, Germany) in $1 \%$ acetic acid solution for $30 \mathrm{~min}$. SRB was then removed and plates were washed for 5 min with $1 \%$ acetic acid. Bound SRB was solubilized with $10 \mathrm{mM}$ Tris buffer, and the absorbance (OD) was measured at $510 \mathrm{~nm}$ using a microplate reader. The half maximal inhibitory concentration $\left(\mathrm{IC}_{50}\right)$ values were determined from the growth inhibition curves.

To reverse the drug resistance, cells were seeded into 24-well tissue culture plates at a density of $2 \times 10^{4}$ cells per well, and pantoprazole (PPZ) (D-78467; Altana Pharma AG, Konstanz, Germany) was added into the cells after 24-h incubation at a final concentration of $10 \mu \mathrm{g} / \mathrm{ml}$, as described in a previous study (32). After a further $24 \mathrm{~h}$, docetaxel was added to $\mathrm{MCF}-7 / \mathrm{CON}$ and $\mathrm{MCF}-7 / \mathrm{CD}$ cells at the final docetaxel concentration of $70 \mathrm{nM}$, while MDA-MB-231/CON and MDA-MB-231/si cells were treated with final concentration of docetaxel of $15 \mathrm{nM}$. All cells were incubated for $48 \mathrm{~h}$, and cell viability was then measured by the SRB assay. Independent experiments were conducted at least in triplicates.

Statistical analysis. A Mann-Whitney U test was used to compare CD147 and V-ATPase H-scores in the chemotherapy-sensitive and chemotherapy-resistance groups of invasive ductal breast cancer. The correlation between CD147 and V-ATPase was evaluated using Spearman's rank correlation coefficient test. All other values were expressed as the mean \pm standard error of the mean, and the Student t-test was used to determine statistical differences between the groups. Values of $\mathrm{P}<0.05$ were considered to indicate differences that were statistically significant. These analyses were conducted using the SPSS version 19.0 statistical software (IBM Corp., Armonk, NY, USA).

\section{Results}

$V$-ATPase is highly expressed in chemotherapy-resistant breast cancer and is correlated with CD147 expression. According to the RECIST criteria, 84 invasive ductal breast cancer patients who had accepted neoadjuvant chemotherapy with four cycles of the $\mathrm{AC} / \mathrm{EC}$ regimen were divided into two groups, including the chemotherapy-sensitive (61 cases) and chemotherapy-resistant (23 cases) groups. The V-ATPase and CD147 expression levels in these samples were detected by immunohistochemical analysis. It was observed that both V-ATPase and CD147 were expressed in invasive breast cancer. CD147 was mainly expressed on the cell membrane, while $\mathrm{V}$-ATPase was located in the cell membrane and cytoplasm (Fig. 1). Furthermore, V-ATPase and CD147 expression levels in the chemotherapy-resistant group were significant higher in comparison with those in the chemotherapy-sensitive group $(\mathrm{P}<0.001$; Fig. 2A and B). In addition, there was a significant 

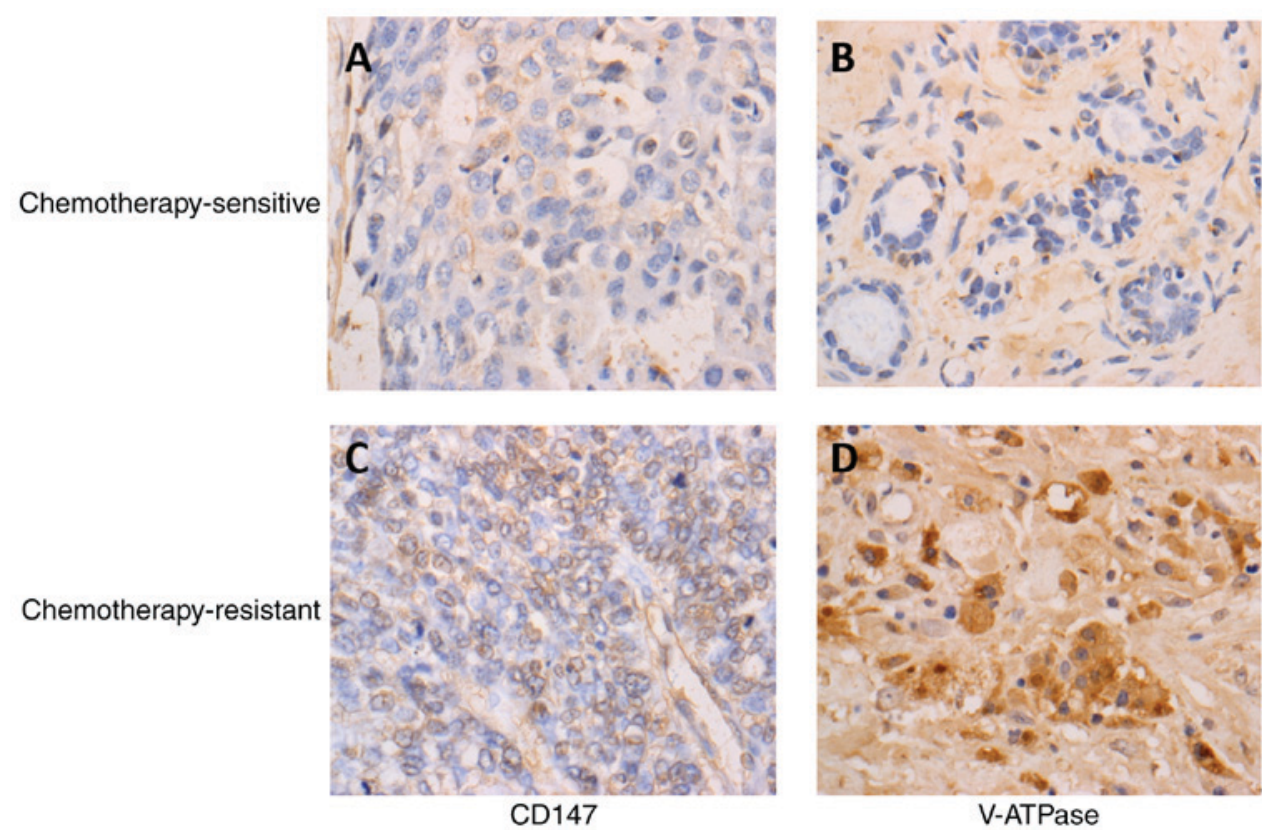

Figure 1. Immunohistochemical observation of CD147 and V-ATPase expression in chemotherapy-sensitive or -resistant breast invasive ductal cancer patients (magnification, x400). Chemotherapy-sensitive patients exhibited moderate expression of (A) CD147 and (B) V-ATPase in the cell membrane. Chemotherapy-resistant patients exhibited high expression of (C) CD147 in the cell membrane and (D) V-ATPase mainly in the cell membrane and cytoplasm. CD147, cluster of differentiation 147; V-ATPase, vacuolar $\mathrm{H}^{+}$-ATPase.
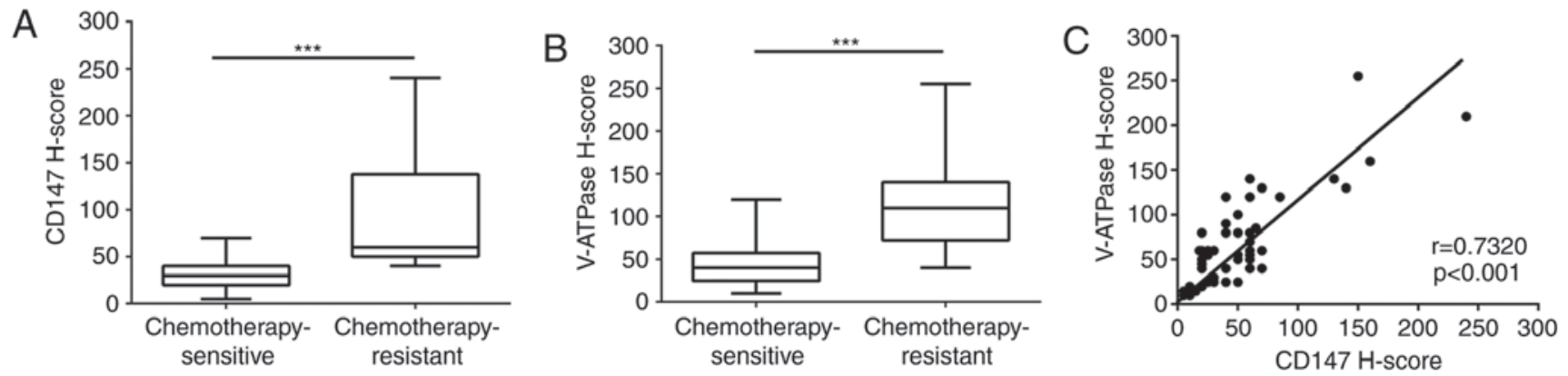

Figure 2. Quantitative analyses of the expression levels of CD147 and V-ATPase in breast cancer samples. Comparison of the expression levels of (A) CD147 and (B) V-ATPase between the chemotherapy-sensitive and -resistant groups. (C) Correlation between the H-scores of CD147 and V-ATPase in breast invasive ductal cancer. ${ }^{* * *} \mathrm{P}<0.001$. CD147, cluster of differentiation 147; V-ATPase, vacuolar $\mathrm{H}^{+}$-ATPase.

correlation between CD147 and V-ATPase expression levels in invasive ductal breast cancer $(\mathrm{r}=0.732, \mathrm{P}<0.001$; Fig. $2 \mathrm{C})$. These results suggested that CD147 and V-ATPase may have synergistic effects in breast cancer drug resistance.

Establishment of MCF-7/CD and MDA-MB-231/si cell lines. Four cell lines were established in the current study, including the MCF-7/CON, MCF-7/CD, MDA-MB-231/CON and MDA-MB-231/si. Total RNA and protein levels from the transfected cells were extracted and analyzed by RT-qPCR and western blot analysis, respectively. The mRNA and protein expression levels of CD147 were significantly upregulated in MCF-7/CD cells as compared with the MCF-7/CON. By contrast, the mRNA and protein expression levels of CD147 were significantly downregulated in MDA-MB-231/si cells as compared with those in MDA-MB-231/CON cells $(\mathrm{P}<0.001$; Fig. 3A-D). These results demonstrated the successful establishment of the transfected cell lines with CD147 overexpression and downregulation that were used in subsequent experiments.
CD147 affects V-ATPase expression and activity. To determine the interaction between CD147 and V-ATPase, the V-ATPase expression was detected in the four cell lines by fluorescence staining. Low CD147 and V-ATPase expression levels were observed in MCF-7/CON cells, while V-ATPase expression was significantly elevated on the cell membrane of MCF-7/CD cells, suggesting that overexpression of CD147 in MCF-7 cells enhanced V-ATPase expression. By contrast, V-ATPase expression was significantly decreased on the cell membrane of MDA-MB-231/si cells compared with MDA-MB-231/CON cells, indicating that CD147 knockdown also decreased V-ATPase expression. These data demonstrated that CD147 affected the V-ATPase expression on the cell membrane (Fig. 4). The V-ATPase activity was also detected, and it was observed that CD147 overexpression was able to enhance V-ATPase activity in breast cancer cells, while CD147 knockdown inhibited the activity of V-ATPase (Fig. 5).

CD147 regulates the transmembrane $p H$ gradient in breast cancer cells. Since V-ATPase serves a critical role in 

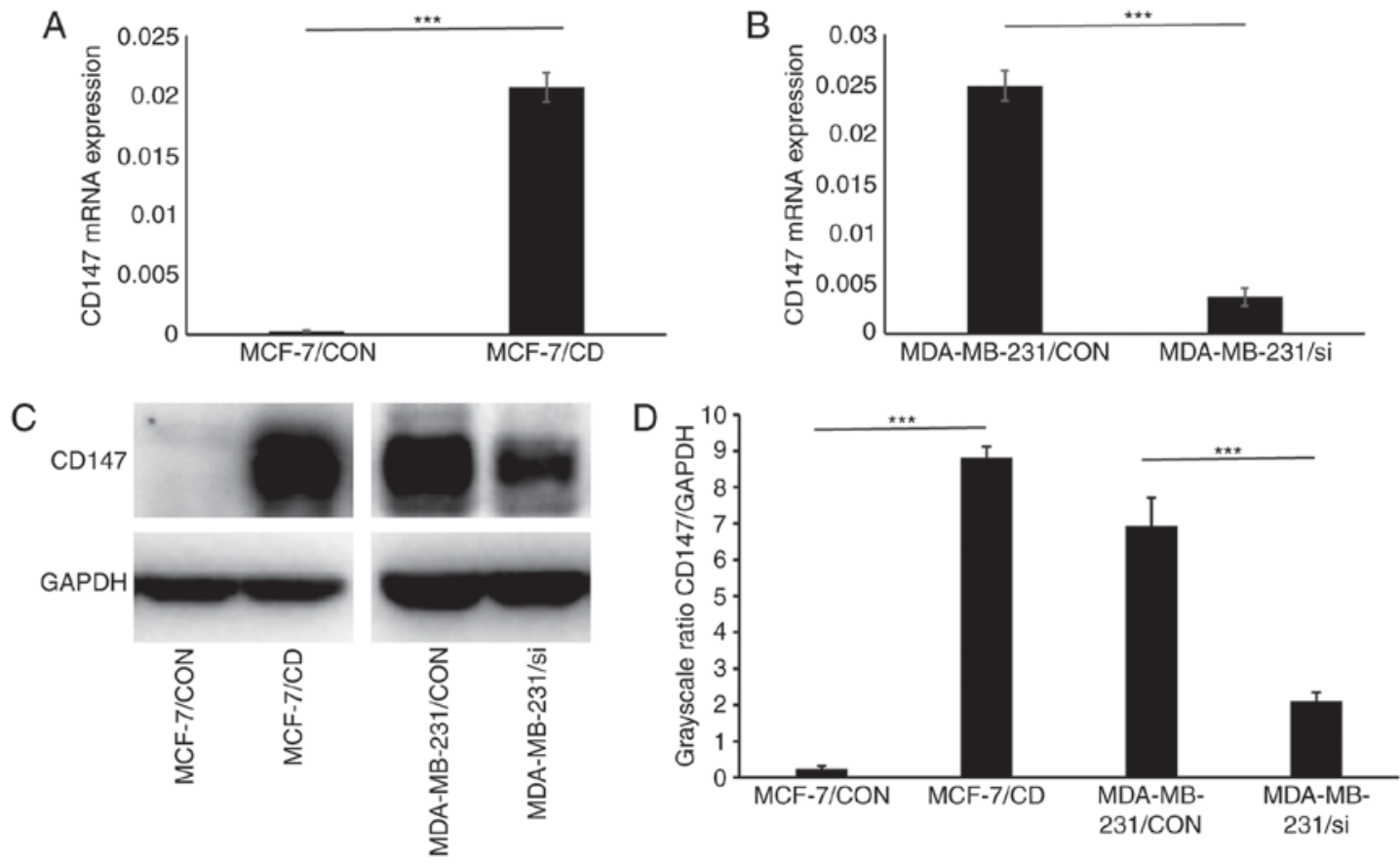

Figure 3. Establishment of transfected cell lines. Reverse transcription-quantitative polymerase chain reaction analyses were used to detect the CD147 mRNA levels in (A) MCF-7/CON and MCF-7/CD cells, and (B) MDA-MB-231/CON and MDA-MB-231/si cells. $\beta$-actin was used as the internal control. (C) Western blots and (D) quantified expression results for CD147 protein in MCF-7/CON, MCF-7/CD, MDA-MB-231/CON and MDA-MB-231/si cells. GAPDH was used as the internal control. Data shown represent one of three independent experiments. ${ }^{* * *} \mathrm{P}<0.001$. CD147, cluster of differentiation 147; CON, control; CD, CD147 overexpression; si, CD147 knockdown.

regulating the $\mathrm{H}^{+}$efflux of cancer cells and $\mathrm{CD} 147$ affects membrane V-ATPase expression and activity, the $\mathrm{pH}_{\mathrm{i}}$ and $\mathrm{pH}_{\mathrm{e}}$ of the transfected cells were determined. The standard curves of the $\mathrm{pH}_{\mathrm{i}}$ value for MCF-7 and MDA-MB-231 cells are demonstrated in Fig. 6A and B, respectively. The $\mathrm{pH}_{\mathrm{i}}$ values of the four cell lines after $24 \mathrm{~h}$ of incubation were calculated according to the standard curve, and are shown in Fig. $6 \mathrm{C}$ and D. Similarly, the $\mathrm{pH}_{\mathrm{e}}$ values of these cells are shown in Fig. 6E and $\mathrm{F}$. The $\mathrm{pH}_{\mathrm{i}}$ value of MCF-7/CD cells was significantly higher in comparison with that in MCF-7/CON cells ( $7.78 \pm 0.06$ vs. $7.41 \pm 0.24$, respectively; $\mathrm{P}=0.001$ ), while the $\mathrm{pH}_{\mathrm{e}}$ value of MCF-7/CD cells was lower compared with that in the MCF-7/CON group ( $7.12 \pm 0.04$ vs. $7.27 \pm 0.03$, respectively; $\mathrm{P}=0.006$ ). These results demonstrated that $\mathrm{CD} 147$ overexpression in MCF-7 cells resulted in $\mathrm{pH}_{\mathrm{i}}$ increase and $\mathrm{pH}_{\mathrm{e}}$ decrease. By contrast, the $\mathrm{pH}_{\mathrm{i}}$ value of MDA-MB-231/si cells was significantly lower compared with that in MDA-MB-231/CON cells ( $7.58 \pm 0.01$ vs. $7.74 \pm 0.02$, respectively; $\mathrm{P}<0.001$ ), and the $\mathrm{pH}_{\mathrm{e}}$ value of MDA-MB-231/si cells was higher compared with that in the control cells $(7.34 \pm 0.05$ vs. $7.20 \pm 0.04$, respectively; $\mathrm{P}=0.02$ ). These results demonstrated that silencing CD147 in MDA-MB-231 cells resulted in $\mathrm{pH}_{\mathrm{i}}$ decrease and $\mathrm{pH}_{\mathrm{e}}$ increase. Taken together, it can be concluded that CD147 was able to regulate the transmembrane $\mathrm{pH}$ gradient in breast cancer cells.

CD147 mediates drug resistance in breast cancer cells potentially via V-ATPase. Using an SRB assay, the sensitivity to two chemotherapeutic drugs, namely epirubicin and docetaxel, was examined in the four cell lines (Table I). For MCF-7/CON and MCF-7/CD cells, the $\mathrm{IC}_{50}$ values of epirubicin were $0.99 \pm 0.08$ and $2.78 \pm 0.16 \mu \mathrm{M}$, respectively, while the $\mathrm{IC}_{50}$ values of docetaxel were $28.54 \pm 3.51$ and $72.13 \pm 4.24 \mathrm{nM}$,
Table I. Different sensitivities of four transfected cells to epirubicin and docetaxel.

\begin{tabular}{lcc}
\hline Cells & $\begin{array}{c}\text { Epirubicin } \mathrm{IC}_{50} \\
(\mu \mathrm{M})\end{array}$ & $\begin{array}{c}\text { Docetaxel } \mathrm{IC}_{50} \\
(\mathrm{nM})\end{array}$ \\
\hline MCF-7/CON & $0.99 \pm 0.08$ & $28.54 \pm 3.51$ \\
MCF-7/CD & $2.78 \pm 0.16$ & $72.13 \pm 4.24$ \\
MDA-MB-231/CON & $10.41 \pm 0.85$ & $14.07 \pm 1.92$ \\
MDA-MB-231/si & $3.19 \pm 0.20$ & $4.32 \pm 1.26$ \\
\hline
\end{tabular}

CD147, cluster of differentiation 147; V-ATPase, vacuolar $\mathrm{H}^{+}$-ATPase; CON, control; CD, CD147 overexpression; si, CD147 knockdown; $\mathrm{IC}_{50}$, half maximal inhibitory concentration.

respectively (Fig. 7A and B). For MDA-MB-231/CON and MDA-MB-231/si cells, the $\mathrm{IC}_{50}$ values of epirubicin were $10.41 \pm 0.85$ and $3.19 \pm 0.20 \mu \mathrm{M}$, whereas the $\mathrm{IC}_{50}$ values of docetaxel were $14.07 \pm 1.92$ and $4.32 \pm 1.26 \mathrm{nM}$, respectively (Fig. 7C and D). These data suggested that CD147 overexpression increased the resistance to epirubicin and docetaxel in MCF-7 cells, while CD147 knockdown enhanced the sensitivity to epirubicin and docetaxel in MDA-MB-231 cells.

PPZ may reverse chemoresistance in drug-resistant tumors by directly inhibiting V-ATPase at the cellular level (32), and the present study investigated whether PPZ reversed the CD147-mediated drug resistance in breast cancer cells. The effect of PPZ treatment on the cytotoxicity of docetaxel was also examined, according to the method described in a previous study (32). No evident effect on cell viability was 

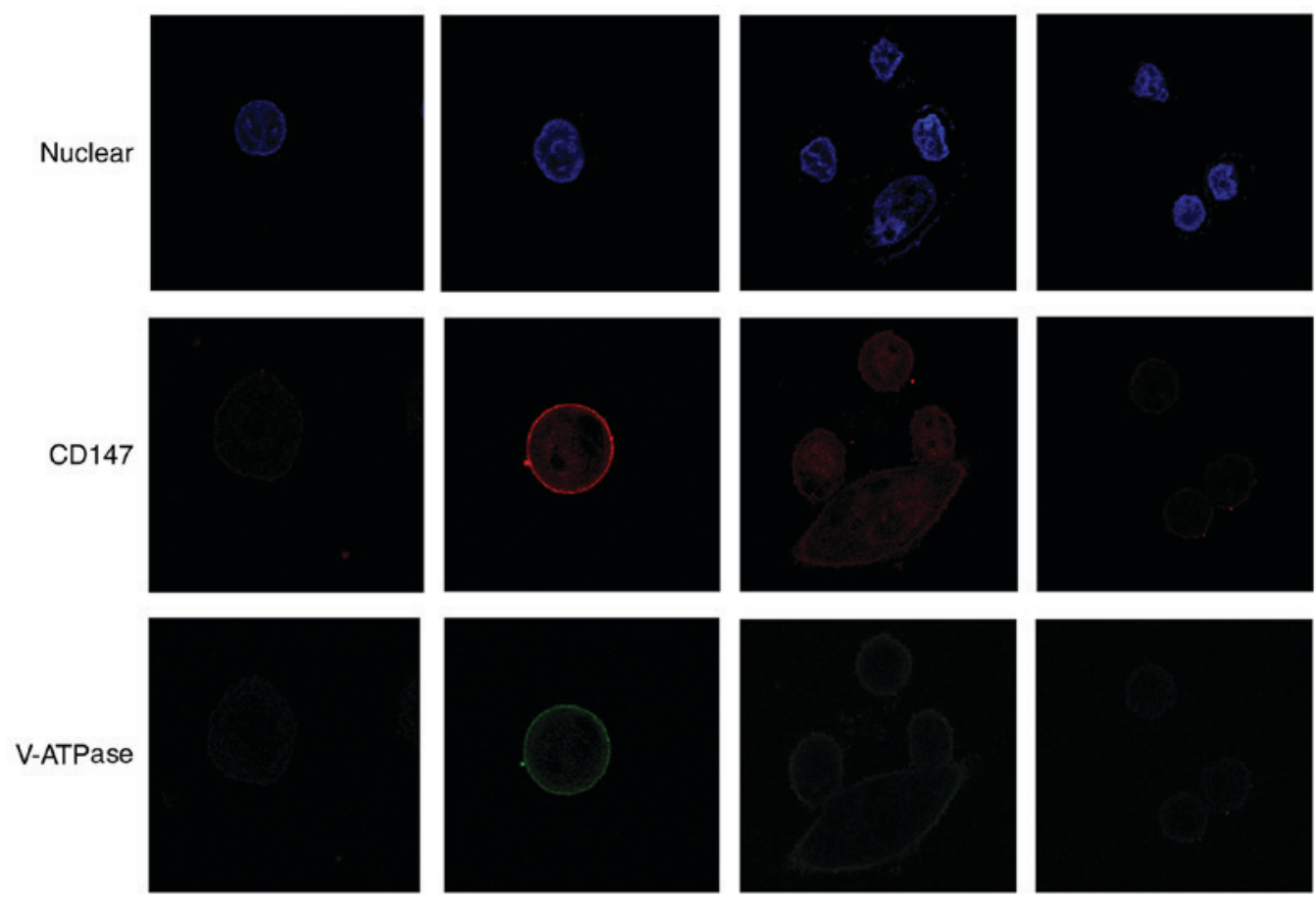

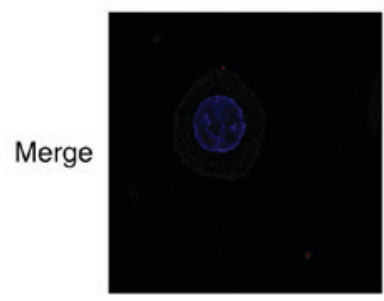

MCF-7/CON

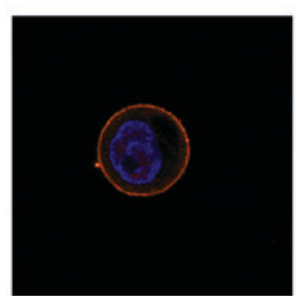

MCF-7/CD

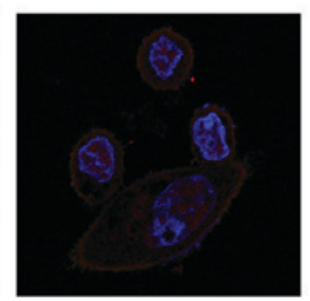

MDA-MB-231/CON

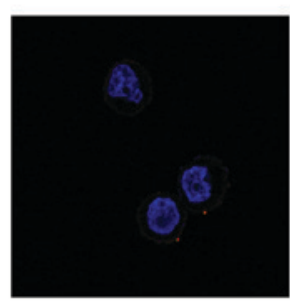

MDA-MB-231/si

Figure 4. Immunofluorescence was used to detect CD147 and V-ATPase expression and subcellular localization in the four transfected cell lines. Experiments were repeated at least three times, and a representative experiment is shown. CD147, cluster of differentiation 147; V-ATPase, vacuolar $\mathrm{H}^{+}$-ATPase; CON, control; CD, CD147 overexpression; si, CD147 knockdown. Blue represents nuclear staining; red represents CD147 staining; yellow represents V-ATPase staining.

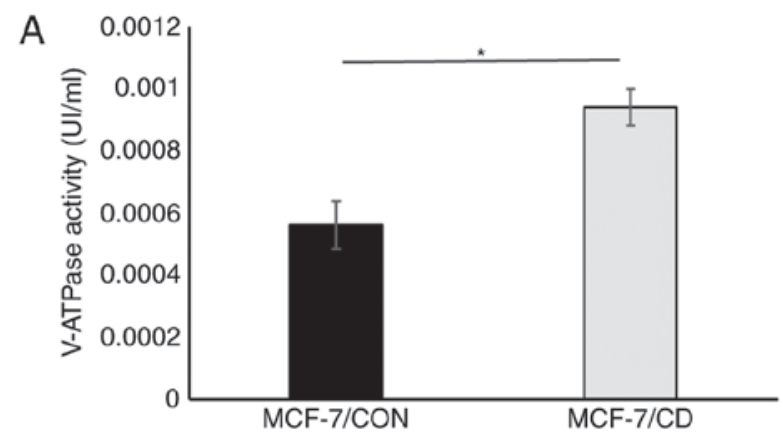

\section{B}

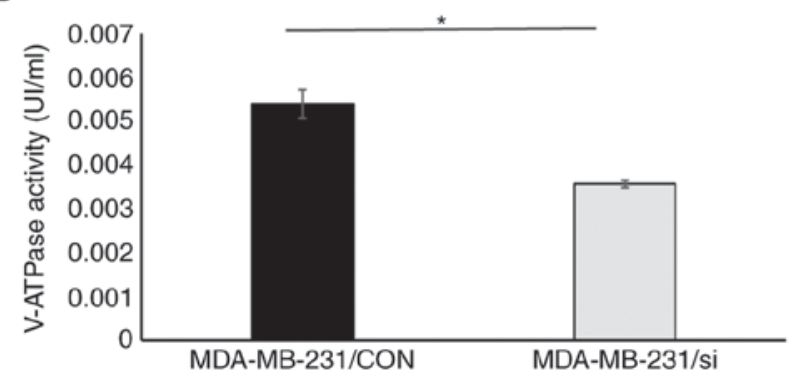

Figure 5. V-ATPase activity in the four transfected cell lines. V-ATPase activity is presented in the (A) MCF-7/CON and MCF-7/CD cells, and (B) MDA-MB-231/CON and MDA-MB-231/si cells. Experiments were repeated at least three times. "P<0.05. V-ATPase, vacuolar $\mathrm{H}^{+}$-ATPase; CON, control; CD, CD147 overexpression; si, CD147 knockdown; CD147, cluster of differentiation 147.

observed at $48 \mathrm{~h}$, and docetaxel was added for a further $48 \mathrm{~h}$ incubation. Cell viability was assessed by the SRB assay following treatment with docetaxel with or without PPZ. The cell viabilities of CD147-overexpressing cells (MCF-7/CD and MDA-MB-231/CON) (25) in the PPZ and docetaxel combined group were evidently decreased as compared with cells in the docetaxel alone group. Furthermore, the results revealed that the cell viabilities of $\mathrm{MCF}-7 / \mathrm{CON}$ cells with docetaxel treatment was lower compared with that of MCF-7/CD cells with
PPZ and docetaxel combined treatment. The cell viabilities of MDA-MB-231/si cells with docetaxel treatment was also lower in comparison with that of MDA-MB-231/CON cells with PPZ and docetaxel combined treatment $(\mathrm{P}<0.001$; Fig. $7 \mathrm{E}$ and $\mathrm{F})$. These observations indicated that PPZ was able to partially reverse the CD147-mediated drug resistance in breast cancer cells. Based on the aforementioned data, it is concluded that CD147 mediated the drug resistance in breast cancer cells via regulating V-ATPase expression and activity. 
A

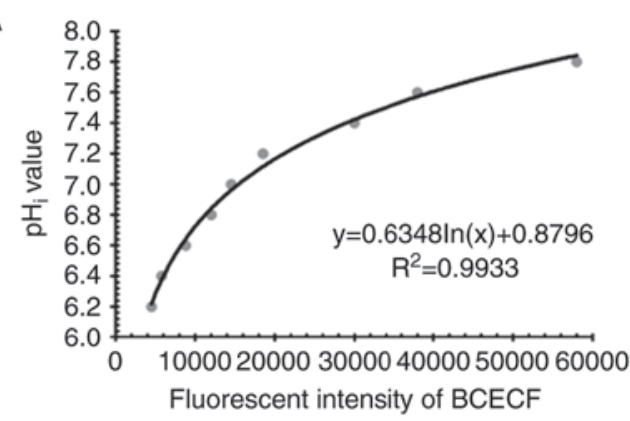

C
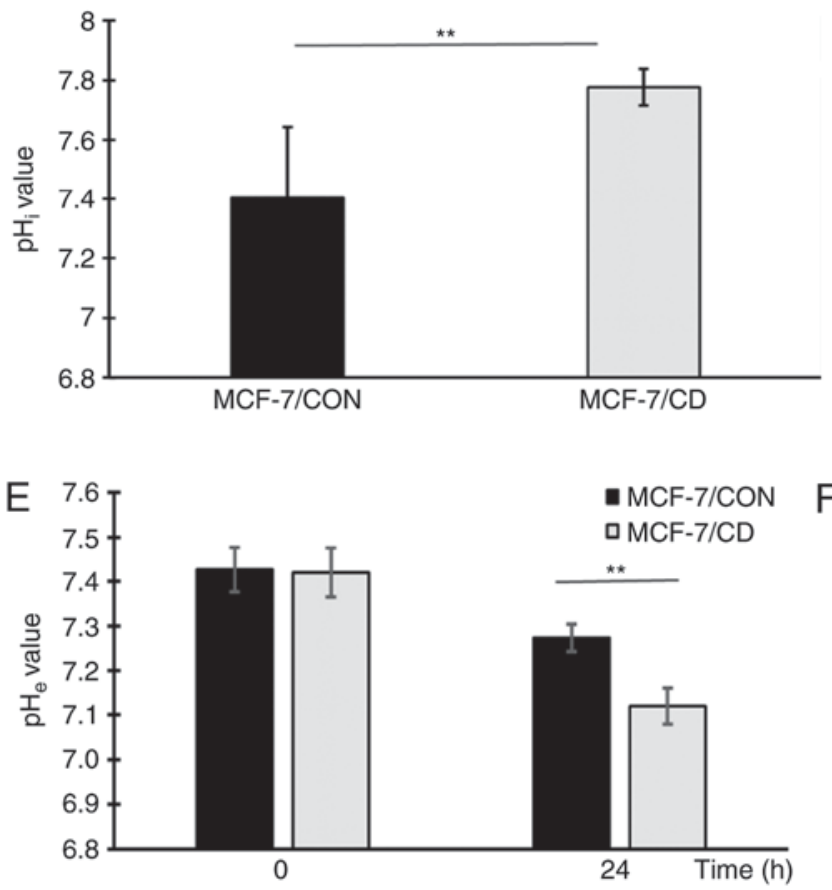

B
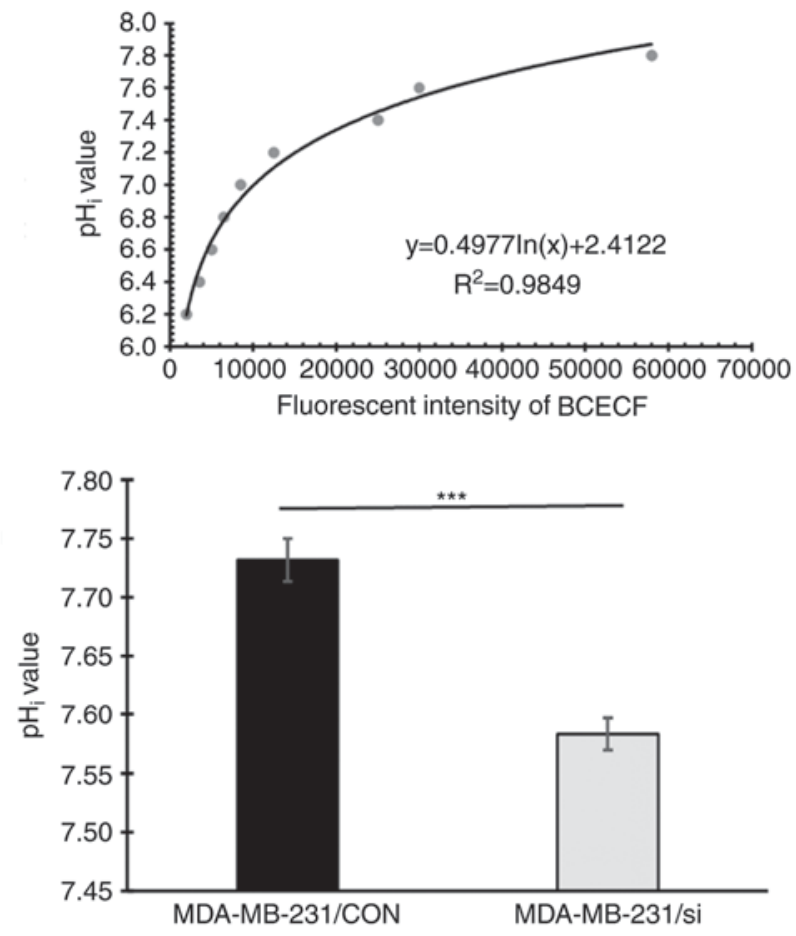

$\mathrm{F}$

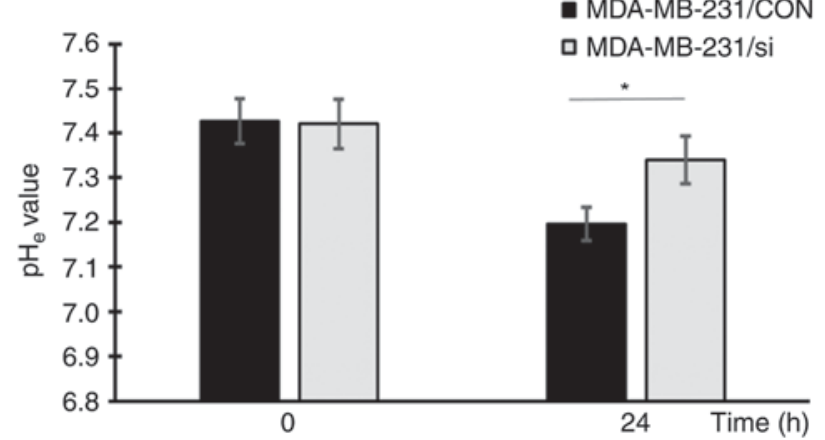

Figure 6. CD147 affects the $\mathrm{pH}_{\mathrm{i}}$ and $\mathrm{pH}_{\mathrm{e}}$ values in breast cancer cells. Standard curves of the fluorescence intensity of $\mathrm{BCECF} / \mathrm{AM}$ vs. the $\mathrm{pH} \mathrm{i}_{\mathrm{i}}$ value of (A) MCF-7 cells and (B) MDA-MB-231 cells. The $\mathrm{pH}_{\mathrm{i}}$ values of (C) MCF-7/CON and MCF-7/CD cells, and (D) MDA-MB-231/CON and MDA-MB-231/si cells are presented. The $\mathrm{pH}_{\mathrm{e}}$ values of (E) MCF-7/CON and MCF-7/CD cells, and (F) MDA-MB-231/CON and MDA-MB-231/si cells are presented. Experiments were repeated at least three times. ${ }^{*} \mathrm{P}<0.05,{ }^{* * *} \mathrm{P}<0.01$ and ${ }^{* * * *} \mathrm{P}<0.001$. CD147, cluster of differentiation 147; V-ATPase, vacuolar $\mathrm{H}^{+}$-ATPase; CON, control; $\mathrm{CD}, \mathrm{CD} 147$ overexpression; si, CD147 knockdown; $\mathrm{pH}_{\mathrm{i}}$, intracellular $\mathrm{pH} ; \mathrm{pH}_{\mathrm{e}}$, extracellular $\mathrm{pH}$; BCECF/AM, 2',7'-bis-(2-carboxyethyl)-5-carboxyfluorescein/acetoxymethyl ester.

\section{Discussion}

The acidic tumor microenvironment serves a critical role in various biological behaviors of tumor cells, including their proliferation, invasion and metastasis, angiogenesis and drug resistance (36). V-ATPase is considered to induce tumor invasion and multi-drug resistance in several malignant tumors, due to its contribution in maintaining the $\mathrm{pH}_{\mathrm{i}}$ under an acidic microenvironment by inducing proton extrusion into the extracellular medium $(12,15)$. The plasma membrane V-ATPase is critical for the invasion and migration of MDA-MB-231 breast cancer cells in vitro (37). V-ATPase expression was elevated in the ellipticine-resistant UKF-NB-4ELLI cell line and mediated its ellipticine resistance via the sequestration of ellipticine into the subcellular compartments (38). García-García et al (39) also demonstrated the overexpression of the V-ATPase subunit $\mathrm{C}$ gene in cisplatin-resistant tumors. In the present study, the association of CD147 and V-ATPase in the invasive ductal breast cancer was investigated by immunohistochemistry. All patients received four cycles of the AC or EC chemotherapy regimen prior to surgery. According to the RECIST criteria, 84 clinical samples were divided into the chemotherapy-sensitive (including 61 cases) and chemotherapy-resistant (including 23 cases) groups. It was observed that the CD147 and V-ATPase expression levels were significant higher in the chemotherapy-resistant group in comparison with those in the chemotherapy-sensitive group. The current study results also revealed that there was a significant correlation between CD147 and V-ATPase expression in invasive ductal breast cancer, suggesting that CD147 may interact with V-ATPase, and this interaction may contribute to breast cancer drug resistance in clinical practice.

Previous studies have demonstrated that CD147 combines with numerous other important molecules on the cell membrane and serves the role of a molecular chaperone, which mediates the biological function of other molecules $(19,40)$. The charged 
A

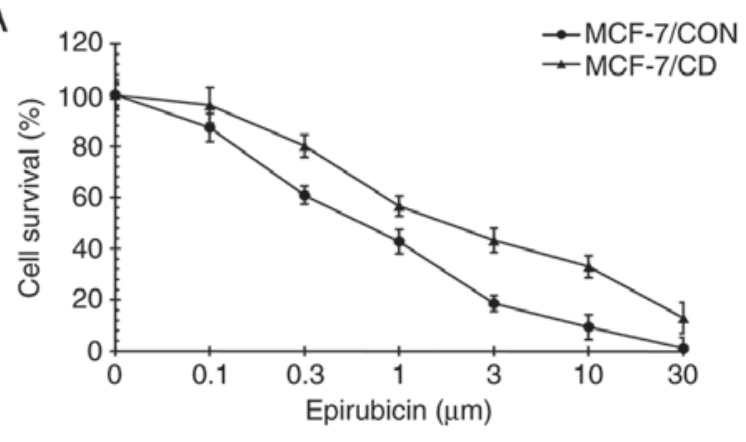

C

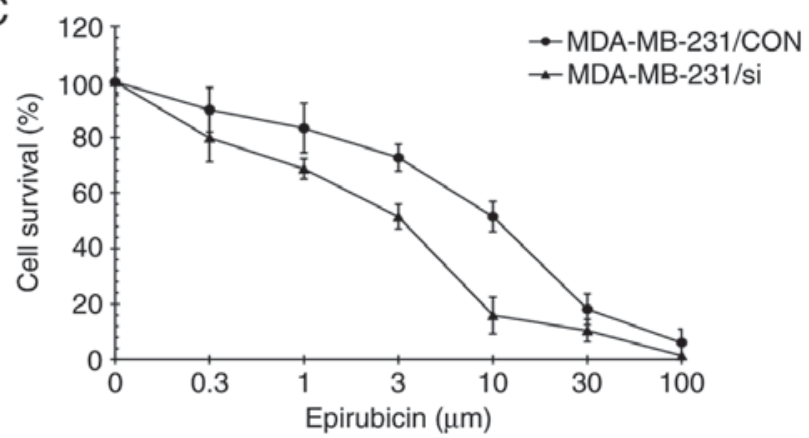

E

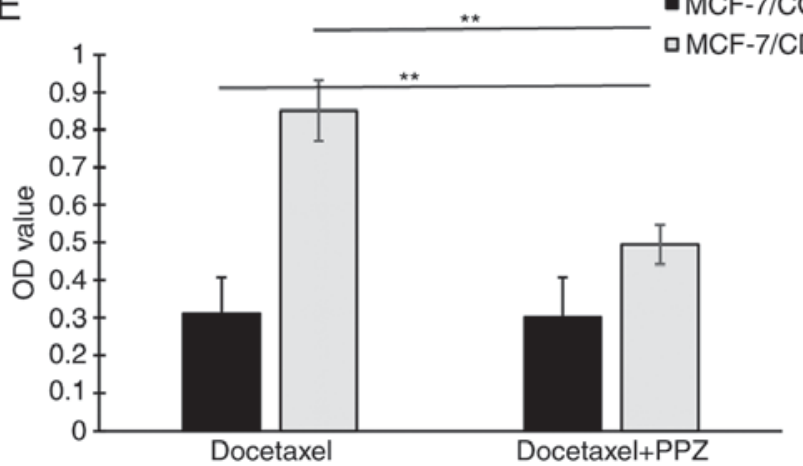

B

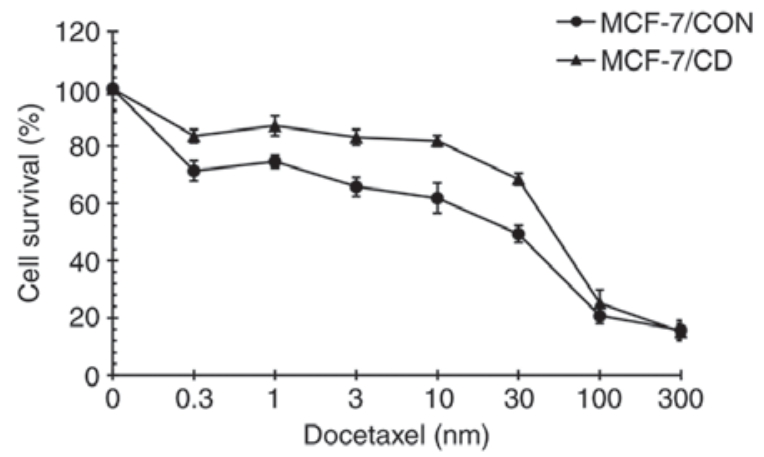

D

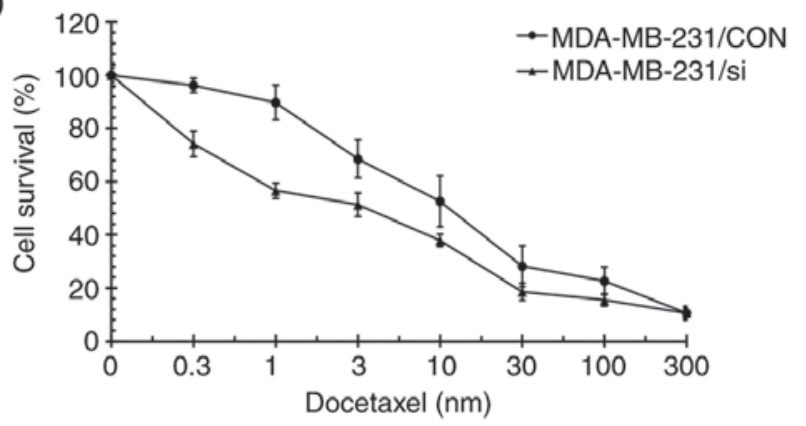

$\mathrm{F}$

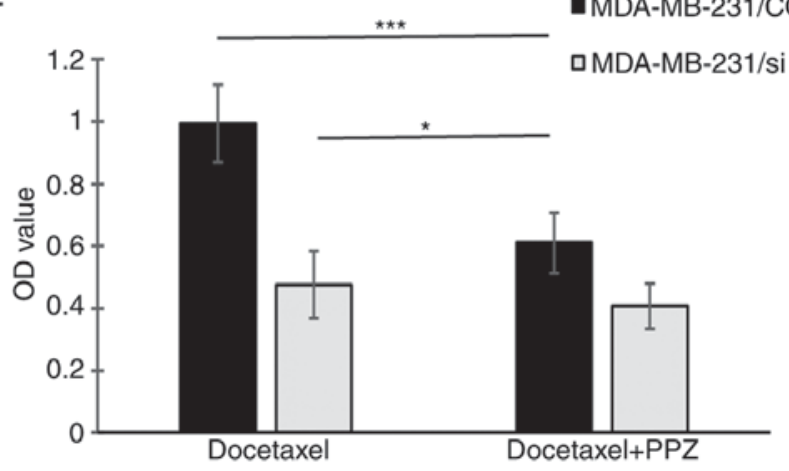

Figure 7. CD147 mediates cell chemoresistance via V-ATPase. The four cell lines were incubated with different concentrations of epirubicin or docetaxel for $72 \mathrm{~h}$, and the relative cell survival was determined by a sulforhodamine B assay. The sensitivity of MCF-7/CON and MCF-7/CD cells to (A) epirubicin and (B) docetaxel is presented. The sensitivity of MDA-MB-231/CON and MDA-MB-231/si cells to (C) epirubicin and (D) docetaxel is presented. Furthermore, the effect of PPZ treatment $(10 \mu \mathrm{g} / \mathrm{ml})$ on the viabilities of transfected cells treated with docetaxel was investigated in (E) MCF-7/CON and MCF-7/CD cells, and (F) MDA-MB-231/CON and MDA-MB-231/si cells. Experiments were repeated at least three times. ${ }^{*} \mathrm{P}<0.05,{ }^{* * *} \mathrm{P}<0.01$ and ${ }^{* * * *} \mathrm{P}<0.001$. CD147, cluster of differentiation 147; V-ATPase, vacuolar $\mathrm{H}^{+}$-ATPase; CON, control; CD, CD147 overexpression; si, CD147 knockdown.

residues and leucine zipper in the transmembrane region of CD147 are potential protein-protein interaction motifs, which possibly mediates its signal transduction involved in the formation of polypeptide chains or membrane transport protein ingredients (41). CD147 is able to interact with proteins such as integrin (42), cyclophilins (43), MCTs (24), ABCG2 (22), hyaluronan (44) and P-gp (45). These interactions may mediate extensive cell biological functions, including tumor drug resistance (40).

The function of CD147 as a molecular chaperone in tumor drug resistance prompted us to explore its association with V-ATPase, which is another important transporter protein located on the cell membrane along with MCT, $\mathrm{Na}^{+} / \mathrm{H}^{+}$exchanger and carbonic anhydrase IX, and contributes to dysregulated $\mathrm{pH}$ in the tumor microenvironment, favoring tumor progression and metastasis (46). The present study investigated whether CD147 interacts with V-ATPase on the cell membrane of breast cancer cells and whether the interaction of these two molecules mediates breast cancer drug resistance. The results demonstrated that CD147 affected the membrane V-ATPase expression and activity, as well as regulated the transmembrane $\mathrm{pH}$ gradient in breast cancer cells, suggesting that $\mathrm{CD} 147$ may regulate transmembrane $\mathrm{pH}$ gradient through affecting membrane V-ATPase expression and activity. It was then observed that the transmembrane $\mathrm{pH}$ gradient changed as CD147 expression was altered, suggesting that CD147 mediated the acidic tumor microenvironment formation, in which V-ATPase may serve an important role. The present study results also revealed that CD147 overexpression increased the resistance to epirubicin and docetaxel in MCF-7 cells, while CD147 knockdown enhanced the sensitivity to epirubicin and docetaxel in MDA-MB-231 cells, suggesting that decreased $\mathrm{pH}_{\mathrm{e}}$ value may cause the chemotherapeutic drug resistance of epirubicin and docetaxel. This experiment was then further verified by PPZ treatment in vitro, which is highly effective in inhibiting V-ATPase. The results indicated that PPZ partially 
reversed CD147-mediated chemoresistance in breast cancer cells. Taken together, these data suggested that CD147 was able to mediate drug resistance in breast cancer cells though interacting with V-ATPase.

CD147 has also been demonstrated to specifically be associated with cell surface expression and the appropriate location of MCTs as a chaperone in the energy metabolism of tumors, thus contributing to the tumor invasion, metastasis and drug resistance (24,47-49). In addition, CD147 have been observed to influence tumor drug resistance through different mechanisms. These include cell survival signaling pathways, drug transporter expression and activity, glycolytic phenotype, and its cancer stem-like cell characteristics (47). However, the present study is the first to observe that CD147 regulates the expression and activity of V-ATPase, thus regulating the transmembrane $\mathrm{pH}$ and mediating tumor drug resistance. The current study findings also suggested that the interaction CD147 and V-ATPase is another mechanism of CD147 contribution to the tumor acidic microenvironment. In recent years, it has been reported that the stability of the CD147-MCT1 complex requires the co-binding of other small molecule chaperones (49). However, it remains unclear whether other small molecule chaperones are required in the CD147-V-ATPase interaction, and the underlying mechanism should be further investigated.

Breast cancer management has entered the era of individualized multidisciplinary treatment, and it is widely appreciated that individualized and novel strategies are required for breast cancer treatment (50). One strategy is the use of proton pump inhibitors which can enhance the tumor chemosensitivity by increasing the $\mathrm{pH}$ of the tumor microenvironment (5). Recent clinical trials in animals with spontaneous tumors have indicated that patient alkalization is capable of reversing acquired chemoresistance in a large percentage of tumors that are refractory to chemotherapy $(51,52)$. The present study also used a PPI to inhibit the function of V-ATPase, leading to alteration of the transmembrane $\mathrm{pH}$ gradient, and the results revealed a certain degree of reversal of the docetaxel resistance. Furthermore, these results indicated that V-ATPase inhibitors have the potential to increase the tumor sensitivity to chemotherapeutic drugs. However, this reversal is not complete and indicates that other mechanisms of drug resistance must exist. These underlying mechanisms are the direction of our future studies, and multigene signatures should be examined to comprehensively identify the drug resistance mechanism of traditional drugs.

In conclusion, clinical and experimental approaches were combined to demonstrate that CD147 was able to regulate V-ATPase expression and activity to mediate drug resistance in breast cancer. The findings of the present study suggested that the interaction of CD147 and V-ATPase may be a good therapeutic target for breast cancer drug resistance. To this end, drugs targeting the CD147-V-ATPase complex, such as monoclonal antibodies, can be specifically developed to overcome the occurrence of tumor resistance. The cytology in vitro results of the present study should also be confirmed in vivo in clinical experiments.

\section{Acknowledgements}

Not applicable.

\section{Funding}

The present study was supported by grants from the National Natural Science Foundation of China (nos. 81101654 and 81573049).

\section{Availability of data and materials}

All data generated or analyzed during this study are included in this published article.

\section{Authors' contributions}

LL and YK obtained funding to conduct the research on the role of CD147 in breast cancer. SW, LT, JH, and GY collected all the blood samples and clinicopathological factors of the patients with breast cancer. LL and YK conducted all the experiments, interpreted the results and drafted the manuscript. All authors participated in the critical revision of the manuscript and have read and approved the final version.

\section{Ethics approval and consent to participate}

All procedures performed in studies involving human participants were in accordance with the ethical standards of the Institutional and/or National Research Committee and with the 1964 Helsinki declaration and its later amendments or comparable ethical standards. Research protocols for the use of human tissue were approved by and conducted in accordance with the policies of the Institutional Review Boards at Central South University (Central South University, approval no. 201403152).

\section{Consent for publication}

All patients from Xiangya Hospital of Central South University (Changsha, China) were informed that their resected tumor samples may be used for medical research and their clinical medical records may be used for publication at admission. Informed consent was obtained from all individual participants included in the study.

\section{Competing interests}

The authors declare that they have no competing interests.

\section{References}

1. Torre LA, Bray F, Siegel RL, Ferlay J, Lortet-Tieulent J and Jemal A: Global cancer statistics, 2012. CA Cancer J Clin 65: 87-108, 2015

2. Baguley BC: Multiple drug resistance mechanisms in cancer. Mol Biotechnol 46: 308-316, 2010.

3. Gonzalez-Angulo AM, Morales-Vasquez F and Hortobagyi GN: Overview of resistance to systemic therapy in patients with breast cancer. Adv Exp Med Biol 608: 1-22, 2007.

4. Moulder S: Intrinsic resistance to chemotherapy in breast cancer. Womens Health (Lond) 6: 821-830, 2010.

5. Taylor S, Spugnini EP, Assaraf YG, Azzarito T, Rauch C and Fais S: Microenvironment acidity as a major determinant of tumor chemoresistance: Proton pump inhibitors (PPIs) as a novel therapeutic approach. Drug Resist Updat 23: 69-78, 2015.

6. Baldini N, Scotlandi K, Barbanti-Bròdano G, Manara MC, Maurici D, Bacci G, Bertoni F, Picci P, Sottili S, Campanacci M, et al: Expression of P-glycoprotein in high-grade osteosarcomas in relation to clinical outcome. N Engl J Med 333: 1380-1385, 1995. 
7. Serra M, Scotlandi K, Manara MC, Maurici D, Benini S, Sarti M, Campanacci $\mathrm{M}$ and Baldini N: Analysis of P-glycoprotein expression in osteosarcoma. Eur J Cancer 31 A: 1998-2002, 1995.

8. Ferrari S, Bertoni F,Zanella L, Setola E, Bacchini P, Alberghini M, Versari $M$ and Bacci G: Evaluation of P-glycoprotein, HER-2/ ErbB-2, p53, and Bcl-2 in primary tumor and metachronous lung metastases in patients with high-grade osteosarcoma Cancer 100: 1936-1942, 2004.

9. Zhao Y, Zhang CL, Zeng BF, Wu XS, Gao TT and Oda Y: Enhanced chemosensitivity of drug-resistant osteosarcoma cells by lentivirus-mediated Bcl-2 silencing. Biochem Biophys Res Commun 390: 642-647, 2009.

10. Song B, Wang Y, Xi Y, Kudo K, Bruheim S, Botchkina GI, Gavin E, Wan Y, Formentini A, Kornmann M, et al: Mechanism of chemoresistance mediated by miR-140 in human osteosarcoma and colon cancer cells. Oncogene 28: 4065-4074, 2009.

11. Kaplan RN, Riba RD, Zacharoulis S, Bramley AH, Vincent L, Costa C, MacDonald DD, Jin DK, Shido K, Kerns SA, et al: VEGFR1-positive haematopoietic bone marrow progenitors initiate the pre-metastatic niche. Nature 438: 820-827, 2005.

12. Kato Y, Ozawa S, Miyamoto C, Maehata Y, Suzuki A, Maeda T and Baba Y: Acidic extracellular microenvironment and cancer. Cancer Cell Int 13: 89, 2013.

13. McIntyre A and Harris AL: The role of ph regulation in cancer progression. Recent Results Cancer Res 207: 93-134, 2016.

14. Trédan O, Galmarini CM, Patel K and Tannock IF: Drug resistance and the solid tumor microenvironment. J Natl Cancer Inst 99: 1441-1454, 2007

15. Damaghi M, Wojtkowiak JW and Gillies RJ: $\mathrm{pH}$ sensing and regulation in cancer. Front Physiol 4: 370, 2013.

16. Avnet S, Lemma S, Cortini M, Pellegrini P, Perut F, Zini N Kusuzaki K, Chano T, Grisendi G, Dominici M, et al: Altered pH gradient at the plasma membrane of osteosarcoma cells is a key mechanism of drug resistance. Oncotarget 7: 63408-63423, 2016

17. Luciani F, Spada M, De Milito A, Molinari A, Rivoltini L, Montinaro A, Marra M, Lugini L, Logozzi M, Lozupone F, et al: Effect of proton pump inhibitor pretreatment on resistance of solid tumors to cytotoxic drugs. J Natl Cancer Inst 96: 1702-1713, 2004

18. Pérez-Sayáns M, Somoza-Martin JM, Barros-Angueira F, Diz PG, Rey JM and Garcia-Garcia A: Multidrug resistance in oral squamous cell carcinoma: The role of vacuolar ATPases. Cancer Lett 295: 135-143, 2010.

19. Nabeshima K, Iwasaki H, Koga K, Hojo H, Suzumiya J and Kikuchi M: Emmprin (basigin/CD147): Matrix metalloproteinase modulator and multifunctional cell recognition molecule that plays a critical role in cancer progression. Pathol Int 56: 359-367, 2006.

20. Yang JM, Xu Z, Wu H, Zhu H, Wu X and Hait WN: Overexpression of extracellular matrix metalloproteinase inducer in multidrug resistant cancer cells. Mol Cancer Res 1: 420-427, 2003.

21. Marieb EA, Zoltan-Jones A, Li R, Misra S, Ghatak S, Cao J, Zucker S and Toole BP: Emmprin promotes anchorage-independent growth in human mammary carcinoma cells by stimulating hyaluronan production. Cancer Res 64: 1229-1232, 2004.

22. Zhou S, Liao L, Chen C, Zeng W, Liu S, Su J, Zhao S, Chen M, Kuang Y, Chen X and Li J: CD147 mediates chemoresistance in breast cancer via ABCG2 by affecting its cellular localization and dimerization. Cancer Lett 337: 285-292, 2013.

23. Qin Z, Dai L, Bratoeva M, Slomiany MG, Toole BP and Parsons C: Cooperative roles for emmprin and LYVE-1 in the regulation of chemoresistance for primary effusion lymphoma. Leukemia 25: 1598-1609, 2011

24. Slomiany MG, Grass GD, Robertson AD, Yang XY, Maria BL, Beeson C and Toole BP: Hyaluronan, CD44, and emmprin regulate lactate efflux and membrane localization of monocarboxylate transporters in human breast carcinoma cells. Cancer Res 69: 1293-1301, 2009.

25. Gallagher SM, Castorino JJ, Wang D and Philp NJ: Monocarboxylate transporter 4 regulates maturation and trafficking of CD147 to the plasma membrane in the metastatic breast cancer cell line MDA-MB-231. Cancer Res 67: 4182-4189, 2007.

26. Zhao S, Chen C, Liu S, Zeng W, Su J, Wu L, Luo Z, Zhou S, Li Q, Zhang J, et al: CD147 promotes MTX resistance by immune cells through up-regulating ABCG2 expression and function. J Dermatol Sci 70: 182-189, 2013.

27. Chen X, Su J, Chang J, Kanekura T, Li J, Kuang YH, Peng S, Yang F, Lu H and Zhang JL: Inhibition of CD147 gene expression via RNA interference reduces tumor cell proliferation, activation, adhesion, and migration activity in the human Jurkat T-lymphoma cell line. Cancer Invest 26: 689-697, 2008.
28. Livak KJ and Schmittgen TD: Analysis of relative gene expression data using real-time quantitative PCR and the 2(-Delta Delta C(T)) method 25: 402-408,2001.

29. Lebeau A, Kriegsmann M, Burandt E and Sinn HP: Invasive breast cancer: The current WHO classification. Pathologe 35: 7-17, 2014 (In German).

30. Eisenhauer EA, Therasse P, Bogaerts J, Schwartz LH, Sargent D, Ford R, Dancey J, Arbuck S, Gwyther S, Mooney M, et al: New response evaluation criteria in solid tumours: Revised RECIST guideline (version 1.1). Eur J Cancer 45: 228-247, 2009.

31. McCarty KS Jr, Miller LS, Cox EB, Konrath J and McCarty KS Sr: Estrogen receptor analyses. Correlation of biochemical and immunohistochemical methods using monoclonal antireceptor antibodies. Arch Pathol Lab Med 109: 716-721, 1985.

32. Chen M, Huang SL, Zhang XQ, Zhang B, Zhu H, Yang VW and Zou XP: Reversal effects of pantoprazole on multidrug resistance in human gastric adenocarcinoma cells by down-regulating the V-ATPases/mTOR/HIF-1 $\alpha / \mathrm{P}$-gp and MRP1 signaling pathway in vitro and in vivo. J Cell Biochem 113: 2474-2487, 2012.

33. Franck P, Petitipain N, Cherlet M, Dardennes M, Maachi F, Schutz B, Poisson L and Nabet P: Measurement of intracellular $\mathrm{pH}$ in cultured cells by flow cytometry with BCECF-AM. J Biotechnol 46: 187-195, 1996.

34. Liao L, Song M, Li X, Tang L, Zhang T, Zhang L, Pan Y, Chouchane L and Ma X: E3 ubiquitin ligase UBR5 drives the growth and metastasis of triple negative breast cancer. Cancer Res 77: 2090-2101, 2017.

35. Vichai V and Kirtikara K: Sulforhodamine B colorimetric assay for cytotoxicity screening. Nat Protoc 1: 1112-1116, 2006.

36. Quail DF and Joyce JA: Microenvironmental regulation of tumor progression and metastasis. Nat Med 19: 1423-1437, 2013.

37. Cotter K, Capecci J, Sennoune S, Huss M, Maier M, MartinezZaguilan R and Forgac M: Activity of plasma membrane V-ATPases is critical for the invasion of MDA-MB231 breast cancer cells. J Biol Chem 290: 3680-3692, 2015.

38. HrabetaJ,GrohT,KhalilMA,PoljakovaJ,Adam V,KizekR,UhlikJ, Doktorova H, Cerna T, Frei E, et al: Vacuolar-ATPase-mediated intracellular sequestration of ellipticine contributes to drug resistance in neuroblastoma cells. Int J Oncol 47: 971-980, 2015.

39. García-García A, Pérez-Sayáns García M, Rodríguez MJ, Antúnez-López J, Barros-Angueira F, Somoza-Martín M, Gándara-Rey JM and Aguirre-Urízar JM: Immunohistochemical localization of $\mathrm{C} 1$ subunit of V-ATPase (ATPase C1) in oral squamous cell cancer and normal oral mucosa. Biotech Histochem 87: 133-139, 2012.

40. Muramatsu T: Basigin (CD147), a multifunctional transmembrane glycoprotein with various binding partners. J Biochem 159: 481-490, 2016.

41. Kasinrerk W, Tokrasinwit N and Phunpae P: CD147 monoclonal antibodies induce homotypic cell aggregation of monocytic cell line U937 via LFA-1/ICAM-1 pathway. Immunology 96: 184-192, 1999.

42. Curtin KD, Meinertzhagen IA and Wyman RJ: Basigin (EMMPRIN/CD147) interacts with integrin to affect cellular architecture. J Cell Sci 118: 2649-2660, 2005.

43. Takahashi M, Suzuki S and Ishikawa K: Cyclophilin A-EMMPRIN interaction induces invasion of head and neck squamous cell carcinoma. Oncol Rep 27: 198-203, 2012.

44. Grass GD, Dai L, Qin Z, Parsons C and Toole BP: CD147: Regulator of hyaluronan signaling in invasiveness and chemoresistance. Adv Cancer Res 123: 351-373, 2014.

45. Li QQ, Wang WJ, Xu JD, Cao XX, Chen Q, Yang JM and Xu ZD: Involvement of CD147 in regulation of multidrug resistance to P-gp substrate drugs and in vitro invasion in breast cancer cells. Cancer Sci 98: 1064-1069, 2007.

46. Jamali S, Klier M, Ames S, Barros LF, McKenna R, Deitmer JW and Becker HM: Hypoxia-induced carbonic anhydrase IX facilitates lactate flux in human breast cancer cells by non-catalytic function. Sci Rep 5: 13605, 2015.

47. Toole BP and Slomiany MG: Hyaluronan, CD44 and Emmprin: Partners in cancer cell chemoresistance. Drug Resist Updat 11: 110-121, 2008

48. Li X, Yu X, Dai D, Song X and Xu W: The altered glucose metabolism in tumor and a tumor acidic microenvironment associated with extracellular matrix metalloproteinase inducer and monocarboxylate transporters. Oncotarget 7: 23141-23155, 2016.

49. Kendrick AA, Schafer J, Dzieciatkowska M, Nemkov T, D'Alessandro A, Neelakantan D, Ford HL, Pearson CG, Weekes CD, Hansen KC and Eisenmesser EZ: CD147: A small molecule transporter ancillary protein at the crossroad of multiple hallmarks of cancer and metabolic reprogramming. Oncotarget 8: 6742-6762, 2017. 
50. Ellsworth RE, Decewicz DJ, Shriver CD and Ellsworth DL: Breast cancer in the personal genomics era. Curr Genomics 11: 146-161, 2010.

51. Ferrari S, Perut F, Fagioli F, Brach Del Prever A, Meazza C, Parafioriti A, Picci P, Gambarotti M, Avnet S, Baldini N and Fais S: Proton pump inhibitor chemosensitization in human osteosarcoma: From the bench to the patients' bed. J Transl Med 11: 268, 2013.
52. Spugnini EP, Buglioni S, Carocci F, Francesco M, Vincenzi B, Fanciulli $\mathrm{M}$ and Fais S: High dose lansoprazole combined with metronomic chemotherapy: A phase I/II study in companion animals with spontaneously occurring tumors. J Transl Med 12: $225,2014$. 